\title{
Extension and the Disposal of the World: Double-crossing systems, culture, self and language
}

\begin{abstract}
Fashion in sociology has moved towards making choice and the individual more central without quite abandoning its more totalising tropes of structure and domination. The proposal in this inaugural lecture is to explore recessive meanings of "disposal" - ordering and arrangement - as a means of making explicit how each of us is emplaced and affected by our extension in the world. Picking up an oscillation in explanation between parts and wholes - production views one moment and consumption views the next - I retrace work on four "gatherings" of Euro-American thought germane to sociology: systems, culture, self and language. The aim is to excavate the recessive arrangements and ordering implicit in each and illuminate the ways extension may be affected by how world is imagined and experienced. With "making a clearing" typically caught in reaction from extant theory - ending up talking say of parts instead of wholes or consumption in place of production - I illustrate instead the methodology of "double crossing" by moving back and forth between older and newer ground to elicit what is unsighted from either view.
\end{abstract}

\section{Introduction}

In this inaugural lecture I have in mind meanings implied in the old adage "Man proposes, God disposes", whereby man (sic) is put in the peculiar position of making pronouncements about how the world works, but is unable to do much about its ordering and arrangement. My aim in raising this somewhat abandoned view of disposal is to find a ground in which to explore its denotation of arrangement and ordering, which I see as mislaid rather than lost. Key connotations for instance continue to carry in everyday phrases, such as "I am at your disposal". Or remain in terms like disposition how someone's outlook affects the way they frame things - and disposable income - how this goes before choice and constrains the way we spend. To this end I attend to how our various relations of extension are pre-disposed, in one way or another, towards "being" this or "doing" that. Hence much of what I have to say runs counter to the modernist trend to refuse disposal, rubbishing its possibilities by using the term only to denote what comes at the end of a production-consumption cycle.

It is helpful to recall how early sociology also put people in the peculiar position of being at the receiving end of a god-like disposal. If its radical moves came from seeing things holistically - capitalism for Marx, culture for Durkheim and modernity for Weber - the dramatic step was to suggest social actors were the "production" of these structures. The idea that class conflict, collective consciousness, or the iron cage produces each of us in terms of agency, conduct or rationality ran counter to Enlightenment teachings of man as sovereign in his (sic) own kingdom. Indeed, to see social actors as emblematic of their class, bearers of culture, or agents of capitalism, not only narrows Kant's "universe within" to proposals by the self to the self, for the self. In terms of extension - including 
agency, conduct or rationality - the very persons making proposals were taken to be under the kind of domination only sociologists and anthropologists could understand.

Expectations today are very different. Post-Nietzsche, people are expected to take charge of things and theory in sociology has moved against overly strict and self-sealing notions of production and agency by giving more attention to consumption and the choice of individuals. What matters to contemporary sociological debate is not, however, what people buy (the province of marketing and economics), but is focused instead on what social forms might be being reproduced through consumption. The effect is to draw on studies of consumption to explain production and reproduction, rather than explain consumption from production. This reversal in direction draws on notions of social construction ${ }^{1}$ that - while leaving open the actual nature of self - move structure away from being a totalising concept towards more indeterminate processes that in turn are themselves undergoing change. What matters in the work Erving Goffman, for instance, is how everyday institutions, such as greetings and civil inattention, are consumed. His idea of strategic conduct, ${ }^{2}$ in which social actors draw on these institutions to consummate performance, opens up a reproduction of structure to impression and opportunism as much as it relies on conformance and consent.

Arguably, this working backwards from consumption to production brings latent aspects of disposal back into prominence. The most striking example of "higher" orderings and arrangements is the deification of "the market" in the neo-liberal use of discourses of rational choice to distract from gross asymmetries in wealth. However, ideas of arrangement and ordering are also incipient in the many ways researchers today look to the work of Pierre Bourdieu in order to reconcile how inequalities, disadvantage and exploitation are animated by the consumption patterns of social actors. Also prominent is the emphasis on studying how networks come into being through the distribution of materials and power, including STS groups who bring into play the artefacts of technology. If the aim in the turn to culture is to avoid the God's eye view, and the reification of systems that so dogged Talcott Parsons' post-war theory, this is often achieved by keeping fieldwork local and specific. In contrast, the refusal in actor network theory to treat individuals as sovereign - stopping them from stepping into the place of the king - appears to lead to a re-emergence of systems theory in all but name.

My proposal is to deploy disposal as a "third term" in order to explore ground made recessive by a tendency to oscillate between production and consumption views. Critically, in seeking to escape the familiar seesaw between parts and wholes, or agency and structure, I want to ask how world ${ }^{3}$ is ordered in ways that keep open the fact that each person finds it arranged differently. This is in preference to asking the more usual question: How are things arranged for this or that set of people? To see the world only in terms of "things" is to take on the very kind of philosophical stance I want to avoid. It is a reductive move that alters the nature of reality and puts in place prejudicial ways of cutting up the world. Against going along with analytical conventions that endlessly divide one school or tradition from another, or pull observation and knowledge apart into separate domains, I concern myself instead with whatever gathers together for people as "reality" - even if partially and only temporarily. In this way I allow persons to be caught or "framed" by the world both as they imagine it and as they experience it. 
To put it differently, my point is that there is always a disposal of the world affecting extension and emplacing performance. Even if structures no longer entail a domination once attributed to them, disposal affects outlook in the form of habitus (or a "system of predispositions"); shapes their ideas through education or thrownness; donates patrons and sponsors by way of kith and kin; and allots them material resources such as capital or disposable income. What I am setting out to do therefore is to re-trace my work on four "gatherings" of Euro-American thought germane to sociology: systems, culture, self and language. In so doing I want to bring to the fore how each of these requires to be put "under erasure" - the crossing-out device favoured by Heidegger to indicate how one's concern is already deeply entangled in the ground on which the topic has previously been worked. There is, however, a subtle methodological difficulty in Heidegger's proposal to create a "clearing" from the ground on which current knowledge stands. This is because Foucault's counter-claim - that we cannot step out of a truth regime suggests the idea of accomplishing a clearing may be illusory. ${ }^{4}$

In place of attempting to make a clearing, with its invariable dismissal of earlier thought, I use the device of two columns to illustrate a different technique which I call "doublecrossing", namely forms of crossing-out that permit "return crossings". 5 Too often academics jettison current theory, as if it were mere landfill to their proposed alternative. Whereas, in truth, much theory is caught within a mode of reaction that typically obscures its dependence upon earlier orderings and arrangements. For example, in seeking to avoid earlier traps such as reification, many theorists get caught instead in webs of individualisation and choice. ${ }^{6}$ Hence the methodology of doublecrossing not only involves holding onto both the older and the newer ground for each gathering, systems, culture, self and language. It requires crossing back and forth between newer and older ground in order to release what is unsighted from either view; and so illuminate the recessive arrangements and ordering implicit in each.

In what follows, I should underline that using two columns to illustrate the method of "double crossing" overstates an ability to be systematic and exact. Specifically, the device of two columns is adopted to slow down, and make explicit, processes of questioning that likely appeared more haphazard and mercurial at the time. ${ }^{7}$ They underline the importance of keeping contrasting perspectives in view (and so avoid the deletion of one by the other). Hence, "crossings" are likely to be a more temporal affair than spatial particularly since any crossing typically entails "crossing out" terms (as with Heidegger's mark of erasure) in order to create room for a different view. What is important to note is how, at any one moment, the adoption of a term belonging to a particular perspective, wittingly or unwittingly, "disposes" us as researchers towards certain ideas and tropes. Whereas, in another moment, we may be caught in webs of a quite different discourse.

\section{Systems thinking}

Let me turn first to systems. With notable exceptions, such as in the work of Jurgen Habermas and Nikolas Luhmann, the concept of system became all but banished from the sociological canon. Yet from the 1950s to the 1970s it was a notion much in fashion. Talcott Parsons, the dominant theorist in sociology at the time, saw system as the "indispensible master concept" 8 and built his nomothetic "action system" as integral to the totalising effects of the "social system". Sophisticated ideas of self-constructing 
systems, such as autopoiesis in biology, were also mushrooming in science to explain differences in cell and brain behaviour. Large companies like IBM and ICI were imagined as "closed" systems, while industries like railways and oil were viewed as systems "open" to technological change and decline. And it was a common convention of the time for everyone to blame anything that went wrong on "the system". 9

The universal use of the term drew me into asking whether there was - even in embryo something akin to a "systems logic". In registering to do a doctorate entitled On Form, I had certainly set out to do more than see the world in terms of "systems" instead of "things", swapping one set of entities for another. Specifically, I had wanted to escape the kind of bivalent logic I intuitively rejected as an undergraduate and was looking for a way of capturing more worldly forms of order and arrangement. The nub of the issue, as I learnt in my postgraduate studies, is that logic is formalised into sets of deductive moves that are truth-preserving; and, importantly, only truth-preserving. ${ }^{10}$ Logic thus ensures moves are valid in themselves, but at the cost of excluding matters of truth - the inductive domain of deriving assumptions and generalisations being left to science.

The systems movement often describes itself as centred on holism. "Wholes" are excluded from science by methods of reductionism (for instance Galileo measured the strength of a ship by the resistance of a single plank).

Systems thinking established the holistic convention of separating system from its environment by imagining a "boundary". This seems misconceived. Consider how what gets included "in" the university system depends on whether the focus is on teaching or research.

In contrast I triangulated the division between system and environment with a third term "purpose". This also allowed me to show how the reigning distinction - open and closed systems - fell apart.
Rejecting the idea of everything being a system, I searched, in its place, for what might distinguish a system from other forms of ordering and arrangement. This ambition to revive "arrangement" from its analytically driven exclusion avoided the trap of assuming wholes are separable entities.

Consider the hand. The holistic argument is that knowledge of what the hand is and what it can accomplish - has to attend to the whole and cannot be reckoned by reference to the workings of each of its parts, the fingers. Contrastingly, I took it to be self-evident that certain key workings of the hand can be grasped by attending instead to the arrangement of the fingers.

Crossing back and forth between these positions of holism and arrangement led me to examine the technology of money. Stepping outside extant definitions of money - as a means of payment or as a store of value - I noted that when money performs as a system other forms of exchange are no longer operable. My argument was brief. Whereas money can buy goods and goods can buy money, we find goods can no longer buy other goods. (I did note an asymmetry here that might bubble up - this is that money gets used to buy money, since various forms of money always exist). And as David Harvey indicates, in order not to "oxidise" 11 and lose value, money needs to buy goods (including other forms of money). So while exchange itself gets perpetuated, the main point is that what is expelled by the money system is all other forms of exchange, with the possible exception of gift-giving. Specifically, in ways that challenge ideas about a more gradual evolution towards modernity, customs known as barter are driven out. ${ }^{12}$ 
This theoretical work - informed by theories of semiotics as much as systems theory led me to limit the definition of systems to those that are self-constructing - autopoietic in the language of biology. Unless we abandon the notion altogether as bankrupt, it seems vital to distinguish genuine "systems" - phenomena that engross themselves and take on a life of their own - from the merely "systematic" - arrangements that are crafted together in the form of a design. The latter would include order that is built up from the fusion of sets of procedures and rules, or machine systems artificially created by the addition of feedback loops such as missile, central heating and production systems. On this last definition, rather than fall into either category, systemic or systematic, bureaucracy might perhaps be better considered as more of a social imaginary. Always in need of ad-hoc amendments and exceptions, it seems bureaucracy can never be brought into existence in the ideal-typical form that Max Weber had depicted.

With the origins of money lost in the recesses of early civilisations, I was looking for an empirical example of this self-constructing phenomenon and Werner Sombart's claim that the invention of double entry bookkeeping was as important as Newton's discovery of gravitation - a claim strongly supported by Max Weber- led me into the archives to trace its origins. Unexpectedly, examination of early documents suggested double entry booking preceded single entry systems. I was then able to demonstrate that this most likely came about because double entry more or less invents itself into a system. The adoption of a doubling of money signs (making an additional credit entry for every debit entry and vice versa) creates the possibility to "balance" accounts (the total of credits equalling the debits). Balancing then forges its own order in ways that begin to force out much of the information to be found in early records. All other recorded information, such as thanks to God, memorabilia about the family, details of storms in a voyage, comes to look superfluous and, in time, gets eliminated in favour of a focus on the monetary details of what has been sold or purchased. ${ }^{13}$ Double entry is on its way to becoming the only way of ordering market transactions and, importantly, will become accepted as such across all the nations of the world.

What is decisive, I think, is that this self-constructing nature creates a system of record keeping that appears both internally coherent and superior to anything that could be designed. What perspective and the vanishing point did to the visual world of painting and drawing, the form of bookkeeping we call double-entry did to the world of commerce and trading. Bringing about a God-given sense of order and objectivity that would become universally accepted, this new ability to measure the periodic accrual of wealth had huge repercussions for the growth of credit and the development of capitalism. Further, its privileging of transaction costs over other forms of information, as I went on to argue in my doctoral thesis, predetermined ways in which income would come to be separated from capital; and so pre-figured the outcome of debates about income measurement that blew up over financial reporting at that time. ${ }^{14}$

In summary, questioning holistic notions of system turned out to be just a first step in putting the more general concept of system under erasure. The latter required a means of stepping outside the confines of an ontological debate about essence-deciding what exists - and crossing over to the theory of signs, namely semiotics and semiology, to engage in epistemological issues - asking "How can we know?" The upshot of this work of double-crossing between analysis and synthesis was to recognise that systems are not entities available to ostension in the normal way. We cannot point to something like 
John Urry's "car system" directly 15 , as I can point to a desk or overhead screen. Rather the most we can do is to trace their synthetic effects by working backwards, identifying what is excluded or ruled out and then going on to observe what kind of world is produced and recreated. This said, not all exclusion implies a system, however systematic it may appear. Albeit exclusion lends credence to matters we call systems, other possibilities remain; and prime among these is the phenomenon of culture.

\section{The turn to culture}

The turn away from holism and abstract notions of system towards grounded, localised studies was already under way when I engaged in a series of field studies of prestigious institutions from the mid-1980s onwards. It was a time when anthropologists were throwing off much of the structuralism of Levi-Strauss and when many sociologists disabused with systems views of society - had refocused on what interactionists called "the everyday"16, in order to contest Parsons' totalising ideas of the social system and his focus on action coalescing around common goals and uncontested norms.

Although Durkheim's idea of a collective conscience had long been roundly dismissed (and similar ideas like Weltanschauung fallen into disuse), what still lingered on into the 1980s were definitions of culture that were built around the idea of people internalising "shared values". This was often linked, if spuriously, to earlier understandings of culture as derived from common languages and communal rituals and much of the advice at the time, especially by those who sought to capture the authentic "organisational culture", revolved around reporting the myths circulated by the owners or gathering everyday stories of resistance. ${ }^{17}$ Contrastingly, the very early analysis of social cooperation, particularly David Hume's, had relied on the notion of habit - connotations of which remain in Pierre Bourdieu's definition of habitus as a "system of predispositions" acquired early on in life. ${ }^{18}$ So either people were taken to hold similar cognitive beliefs (whether springing from language or place). Or they were depicted as reproducing customs more or less mechanically; not only because things were always done this way, but also because ways of doing are taken to be institutionalised as well as embodied.

The approach I adopted in getting inside each institution departed from these traditions and was two-fold. On the one hand there was an emerging emphasis on consumption, both in the work of Mary Douglas on belonging and in the instruction by actor-network theorists such as Bruno Latour "to follow the technology". Each of these movements, in their different ways, might be thought of as linking back to a long held dictum to read other cultures through the artefacts of their technology. On the other, my interest in ethos ${ }^{19}$ - as potentially distinct from culture - was sharpened by access to one key site where I found myself researching the absence of one particularly modern technology, notably budgets; conspicuous in a market leader in the financial services. ${ }^{20}$ Insofar as I began my ethnography by trying to pick up on the everyday conduct of people in the form of what they said to each other (and grasp how different relational positions in the institution affected this), what I found to be most helpful was Harold Garfinkel's treatment of such everyday exchanges as "accounts". 
My mentor at the time, Anthony Cohen, argued that ideas of culture as "shared values" is a mystification. On the basis that access to what's going on "inside" people's heads is closed off, he pointed to there being an empirical bar to knowing meanings or values.

Tying exclusion to "matter out of place" 21 Douglas' The World of Goods explicitly offers instead a consumption thesis of culture that equates choice in goods with displays of belonging. In Douglas working back from everyday purchases to displays of belonging, she seems to be suggesting a more open (and empirically checkable) process by which culture is always being recreated. ${ }^{22}$

Her approach thus looks to reverse earlier emphases on production views which either mistook culture to be a holistic system that pre-determined values, or assumed ethos is built up from ritual and habit. What is of concern, however, is how her model smuggles in the hidden premise of signalling systems being shared. ${ }^{23}$
Initially I married my attention to technology and its artefacts to a focus on ethos that was more localised as well as being interactive. To avoid conflating ethos with formalised ethical rules of behaviour, I adopted much of Harold Garfinkel's emphasis on researching "the moral world without". 24

In supposing ethos to refer to those elusive ways of doing "membership" that pass muster rather than monster ${ }^{25}$, I stressed the term conduct over that of behaviour. In departing somewhat here from Douglas over how group works, I also gave especial emphasis to the circulation of accounts. Vital in understanding performance is Garfinkel's notion of "passing", which undercuts assumptions of fixed arrangements. While a circulation of accounts in the form of what members repeatedly say to each other may well stabilise the possibility of signals being shared (as with the argot of a band of thieves), "passing" looks wide open to interpretation and hence to the nuances of Goffman-like presentation and performance.

Help for criss-crossing back and forth between these contrasting theories of group came from Marilyn Strathern's work on extension and relations. ${ }^{26}$ Arguing that membership as with all relations - is "partial and provisional", led me to contest the long-standing claim that Garfinkel's work on everyday accounts lacked a theory of power. What I noticed, in the light of this partialness and provisionality, was that persons subtly but continually seek affirmations of membership from each other in all they do and say. It is this inherent doubt about who is really a member - and I might add often considerable uncertainty over exactly what one is a member of - that gives members a form of power to exercise over each other. This is to argue that, while members have little authority over each other, they retain discretion. They have the discretion to stop accounts, challenging what someone else is saying, and even "call" for more accounts. Hence, whenever they let an account "pass", they are, implicitly, "passing" each other as a member. What is of interest in the field therefore are the accounts that get "stopped". What matters as much as those that circulate are accounts from which people detach themselves; those that they refuse to "pass" onto others.

To seek a clearing from notions of culture seems a tall order. Given the burgeoning of culturally informed studies, to say nothing of loose talk about cultures of secrecy, cultures of waste, cultures of excellence, and so on, what, if anything, would be left? To the contrary, there seems more merit in continuing to cross back and forth between the anthropological visions of culture as working around artefacts and sociological arguments about ethos in terms of a domination over how people are "brought up" in 
institutions, be they family or a form of employment. Indeed, as I discuss in the next section on self, my ethnographic materials suggest people's attachment to cultural artefacts might be better understood as "cultural performance". ${ }^{27}$ This is to note how alignment with the artefacts of certain technologies not only helps in "passing" as a member of this or that group, however poorly defined, but works also to make persons "visible and available" to the agendas of others. ${ }^{28}$ Where displays of materials reflect asymmetries of power (and when would they not?), the field is open to strategic conduct and cannot, as Douglas presumed, be a credible source for reading off values and beliefs.

\section{Extension and self}

Implicit in much thinking and argument about culture and ethos are different ideas of self. While some would do away with this will of the wisp, with theories of subjugation and domination, most agree a minimal agency is required to animate such matters - to put the whole machinery into motion. This might take the form of admitting "bearers of culture", persons who keep ways of being in circulation by performing various rites and rituals. Or it might take the form of "exemplary figures", people who conduct themselves in moral ways that others follow. Inevitably the question of which structure is providing what kind of agency has brought the figure of "the self" under increasing scrutiny.

Self, for many, continues to refer to the Kantian figure of man (sic) as sovereign over his individual consciousness. Yet images of this solitary self have been under constant critique. In addition to attempts by $20^{\text {th }}$ century philosophers to 'decentre' self through their work on language, as I discuss later, others speak about multiple or hybrid selves. The idea of multiple selves is illustrated by Alfred Schutz's observation that the ruthless businessman by day can be the loving father by night. This idea allows different spaces, or "worlds", to elicit different dispositions, but abandons Kant's ideal of self as accountable to self. More radically Donna Haraway portrays us as cyborgs -part human/part machine, drawing out the prosthetic relations in technology. ${ }^{29}$ Just as the prosthetic of a wooden leg helps the one-legged to walk - or the swinging of his hammer helps Heidegger nail his roof - so we can go on to ask how much of what we accomplish would be impossible without extension by virtue of our technologies?
Giving a double meaning to the "attachment" afforded by prosthetics, Marilyn Strathern suggests how relations are bodied forth. In so doing, she untangles much earlier debris created through a tussle of top-down and bottom-up definitions of culture.

While couched initially in the language of parts and wholes, her handling of extension obviates the need either to reify matters like culture and self or deny their significance. Specifically, by taking us to be always and already in manifold forms of relations, she cuts out needless speculation about multiple cultures and multiple selves. Culture and self, for her, are not things in themselves, but result from whatever is being performed in the here and now.

What is of equal interest are the relations underpinning "cultural performance" (see previous section). Hence it is still possible for Strathern to talk about culture rather than cultures, since the manifold nature of relations allows the partial and provisional composition of culture to be more abundant and profligate in its heterogeneity than one can ever imagine. 
What my research began to clarify were the implications here for understanding self. Whereas a consumption view might endorse Hume's argument that self is often in flux seldom settling down to being one thing rather than another - conventional models of self tend to assume a mastery of technology that picture persons as travelling outwards from Kant's "inner" self in order to attach to one set of artefacts - a spade or a proverb and then retreating back inwards to this core self before once more going out again to attach to something else. Similarly, in terms of joining up with other persons, ethos is imagined as being forged through building up from what's called "relationships"; this is the process of me or you reaching out to attach to one or more persons, then retreating back inwards to ourselves - before going out again into another relationship.

In contradistinction to all this, my work pointed out that selves are already in extension. And argued that they must always and already be so. To elaborate, much as I am illustrating in these examples of double crossing, my image of self is one of each of us always and already moving across attachments. This involves linking up, partially and provisionally, with another set of relations without necessarily detaching altogether from earlier relations. In other words, rather than seeing ourselves as coming out from self into enhancement and then returning back in, ${ }^{30}$ we might imagine self more as augmented, temporarily, by one form of extension more than another. Indeed, so much so, that we can say that extension is all we are ever "in". ${ }^{31}$ Extension means self is always situated - and necessarily so - within relations of one kind or another. As such, it is time we rejected images of a mobile entity moving independently and freely in and out of one culture to another, or from one self to another, at will.

Since any attachment or detachment is partial and provisional, relations can vary depending on the conditions of possibility on the one hand and affect on the other. In all this, attachment has a double meaning; as is illustrated by the portrait of Father in Tristram Shandy - unable to sleep in his chair by his compulsion to wait for the unoiled parlour door to creak. ${ }^{32}$ However, this doubling of attachment brings up the question of how a movement from one set of relations to another is performed or brought about? Surely, having arrived in one set of relations, we need a form of internal agency to avoid being stuck, like Father, within the maw of that form?33

The notion linking culture to self I found helpful here was not habitus, since the way Bourdieu uses the term exactly carries the idea of being stuck in a "system of predispositions" 34 , but "thrownness". Heidegger argues that we are "thrown" into the world in very specific circumstances: long before we assert anything called selfconsciousness, we are already being brought up speaking a certain language and conducting ourselves in particular ways rather than others. ${ }^{35}$ To admit possibilities of attachment being induced by our upbringing or emplacement is certainly to allow aspects of culture to have bonding qualities. But rather than insisting on culture being some holistic system gluing us together, we can allow that its heterogeneity and composite nature affords different passions to be excited by different technologies: compassionate one moment, selfish the next. ${ }^{36}$

Heidegger goes further here to consider what he calls Gestell. ${ }^{37}$ This enframing or emplacement of us by technology makes us available as a standing resource and here I have drawn attention to the material ways in which certain relations are drawn into the nexus of power by being punctualised. ${ }^{38}$ Punctualising an identity is to call for a cultural 
performance in which certain relations are adhered to over others. It might be to answer the call to be a responsible professional or loyal employee one moment and in the next to answer the call to arms and go on strike. What is key to understanding the exercise of power over identities is that this "ordering" is often made invisible by a manipulation of materials and arrangements. In ways reminiscent of Marx, it might be said there is much false consciousness in those who believe themselves to be "choosing" identities.

Whether called upon by others to punctualise our identity or not, we seem constantly to be having to dispose of the world as we see it one way and then dispose of it in another. In this respect my work with Joanna Latimer has identified motility as being key to movement and the more invisible forms of power. ${ }^{39}$ In place of the current fashion to extol mobility, motility not only enables us to unstick ourselves from any one set of relations - enabling us to cross back and forth between one "outlook" and another - it accomplishes this by moving our attachments, in both senses, towards another set.

Joanna and I do not pretend to know how motility actually works, although there may be a kind of return of the repressed in all this. ${ }^{40}$ For instance, given that disposal implies a form of rearrangement rather than merely getting rid of something, it is likely that one form of landscaping the world can only push other things out of sight for so long. A kind of Gestalt effect perhaps, whereby involuntarily the duck replaces the rabbit? What we can say though, from our ethnographic observation, is that the seamlessness of this movement can sometimes make it appear as if we have also shifted "worlds": the affect is to dispose, in both senses of the word, of one outlook for another. But this issue leads on to the final gathering, namely language.

\section{Language and folding}

If the portrait of extension which I have just painted accords with Heidegger's inquisition of technology as something humans are unable to "master", ${ }^{41}$ its decentring of the Kantian ideal of self has also gained support from the turn to language in $20^{\text {th }}$ century philosophy. This should not surprise as language can lay claim to being the oldest technology. Taking this approach though puts into question the popular belief that language is uniquely mine, ${ }^{42}$ as well as the countervailing view that it is simply "shared" as a communal system of communication. Indeed, Heidegger's argument about "thrownness" implies each of us is brought up in a particular language - and within the peculiarities of place - long before anyone can claim to have the kind of selfconsciousness that can begin to question what they are inheriting. ${ }^{43}$

What is striking, when viewed as a technology, is that language appears to be as much inside us as it remains outside. Unlike the hand, the arrangement of which arguably developed to pick up tools and put them down, the head never seems free of language. Even if we do not join the early Derrida to valorise writing over speaking, thought and language appear entirely intertwined. As the German linguist Max Muller insisted, there is no thought without language and no language without thought. So much so that much continental philosophy aimed itself at deconstructing the long held belief that language is a second-order representation of thought; and a rather poor imitation at that. ${ }^{44}$ 
These debates, including Wittgenstein's thesis against a private language, led me to to consider the main difference lies in how we keep language. While it is easy to set out how we store physical prosthetics what is needed, say, for building, writing and gardening 45 - we fail to notice how we squirrel away artefacts of language phrases, numbers, formulae and stories. As the psychologist Jerome Bruner suggests, stories are key: as well as helping to learn language, they afford a means to "store" experience in narrative form. ${ }^{46}$ Once stored as stories (and the common root of the two words is easy to miss), narratives need not be kept to hand, but might jump up like jack-in-theboxes, surfacing unexpectedly or recalled as occasion demands. I have in mind those troubling events when affect turns us over, rather than around; occasions when we experience a momentary loss of narrative. ${ }^{47}$
If this way of seeing stories draws on Heidegger's contention that we "dwell" in language, it also re-emphasises a growing recognition over how culture and language are also inextricably intertwined. If language were deployed only as mere representations of events, we might find ourselves jettisoning much of our experience. Yet not only do we keep much stuff we inherit, we also tend to hang onto experiences until we make sense of the "buzzing blooming confusion". This suggests language is affective in its nature as much as it is instrumental. Words not only attach to other words, as in the qualifier "red" in "red apple", they double the attachment to give depth to meaning, as in pronouncements about a good person, or true friend. Consequently, as has been recognised in discussions of language games, meaning is not just about reference, pointing to the apple, but very much about using qualifiers to "move" others about. 48

Far from verbal forms of language being "neutral", with words merely denoting things in the world, phrasing and affect weave together complex forms of sense-making that endow resonance as much as they afford recognition. ${ }^{49}$ My preliminary studies suggest that language, in keeping experience and storing stories, not only informs what we are to see, but also landscapes itself in order to do so. The key is to recall that before the gardening wars of the $18^{\text {th }}$ century - particularly the revolution brought about by the picturesque - landscape is that which we look out from, rather than it is what we look at. ${ }^{50}$ It is what gives a vantage onto the world, helping put it into focus. If this "outlook" becomes a device by which we then turn the world into picture ${ }^{51}$, it is first and foremost what helps us arrange and order the categories of things, putting into form and shape what gathers together and also what we keep apart. Inasmuch as language is always and already busy "folding" up the affect of our experiences into stories and other mnemonic devices, the landscape we look out from is intricate, convoluted, motile and recessive.

This idea of language as always and already being busy landscaping, ordering and arranging itself, as seems fit, draws on complex notions of form that go well beyond the bivalent oppositions noted by early structuralists like Saussure. ${ }^{52}$ The upshot is that, while arranging and ordering itself into forms and grounds so that we can "look out" to see and make sense of what is happening, language obviates the very means by which it is helping us see "world" as this or that. This line of thinking - that language is to be understood as a labyrinth of roots and foldings rather than a veil 53 - might go some way to explain why it is so difficult to cut through fashionable language and rid ourselves of extant ways of looking at things? In my understandings of how language works world for each of us, one story can cover up another and one fold of experience can mask an earlier. We do not just have blind spots brought about by forms like a Moebius strip. ${ }^{54}$ 
Rather, to heighten the trope, language landscapes experience through tunnels, potholes, mountains and rivers. Yet, in consequence, a buried story or felt hurt might worm or jack-in-the-box itself back into reflection at any time.

Even larger difficulties lie in the way of working backwards to identify our lines of sight - the disposal of worlds brought about by our "outlooks" - call them landscape, perspective, paradigm or whatever. This is in part why attempts to make a "clearing" turn out to be so laborious; putting ideas "under erasure" is to do far more than merely wish away the ground from which we see. Hence, in this section, I have elaborated a crossing back and forth, from arrangements of language that privilege the place of stories, towards orderings that link language intimately with cultural experience. Certain language systems as I go on to discuss next, like prices or budgets, might appear to take us out of this link, but only at the cost of making the arrangements and orderings of the world even more hidden and recessive.

\section{Concluding comments}

In a world overfull of "things", it is hardly surprising moderns should mislay meanings of disposal as ordering and arrangement and slant its denotation instead to our major problem: namely how to remove, discard, or dump whatever appears inconvenient or in the way. Yet "rubbishing" is not the only form of disposal and it is one of Mary Douglas's seminal insights to have noted that, in addition to having stuff we discard as "below thought", that there is much we also treat as "above suspicion". ${ }^{5}$ This last ranges from tacit understandings about the everyday to "uncontroversial" background knowledge shared by scientists working in a particular tradition. ${ }^{56}$ In working backwards from this insight, I am arguing that the more general meanings of disposal - arrangement and ordering - offer themselves as a means for sociological thought to escape the modernist tendency to streamline notions of reality by merely getting "rid" of things - dismissing whatever does not fit into science as "anomalies" 57 , damning unusual conduct as "deviance" 58 , or discarding the disadvantaged as "normal rubbish" 59.

Instead of treating disposal as solely tied to waste, a mere afterthought to the main focus on production and consumption, I have suggested disposal may also come ahead - in the form of "worlds" that prefigure all we do and presage all we say. This is not only because current understandings about arrangement and order are prefigured by the pathology of modernity, a streamlining that little hesitates to remove anything in the way of what is taken to be progress. It is also because system, culture, self and language are in practice so intermingled and conjoined that their reduction into stand-alone fields of study is nothing short of disastrous. While sociology has moved on from the "wars" which led Randall Collins to sharpen up the boundaries of thought that kept apart what he called our four traditions ${ }^{60}$, the government-induced emphasis on "quantifying" research findings has tended to elide the equal importance of reflecting on premises, hidden and stated, and hardened the practice of researchers working within a pre-set perspective; perspectives in which one way of looking at the world typically cuts out another.

In this inaugural I have therefore sought to go back over my tracks to see if I could discern a methodology commensurate with this reassessment of disposal as ordering and arrangement, rather than be solely concerned with the removal of "out-dated" ideas 
as "waste". My aim has been to explore whether double-crossing offers a way out of the over-worn technique of "rubbishing" competing perspectives in order to privilege one's proposed alternative. Double-crossing thus incorporates Heidegger's emphasis on making a clearing, but without buying into the emphasis on "getting rid" of a prior theory or dominant view. As I have tried to illustrate, there are advantages of crossing back and forth between newer and older ground. Not the least of these is the phenomenon of motility, the way "world" oscillates with focus or argument. Indeed we should not be surprised if viewing things one moment in terms of, say, production - and then consumption the next - results in narratives of unintended consequences and stories of the failure of markets.

Critical to a more informed rethinking of disposal than I can accomplish here is to grasp this issue of motility: how perspectives or interpretations appear to be obviated one moment and yet brought back into play the next. What I want to stress for the moment, therefore, is not the validity of one particular line of argument or the truth of any specific finding. Rather, given the speculative nature of the kind of exploration I have undertaken, the point of illustrating the methodology of double-crossing is to set out a way of working others can follow - even if their follow-up leads to different conclusions. In keeping open findings and conclusions, ${ }^{61}$ I should add that I am not valorising the current fashion for treating ideas merely as matters of opinion or of accepting difference as always something to celebrate. Tolerance to difference in extension is laudable for the most part, particularly in terms of self and language, but may all too easily slip into a laxity over inequalities or disadvantage; and thereby eclipse attention to everyday struggles and conflict. So, too, the practice of insisting researchers select one from a range of multiple perspectives has served well as a device to counter those who insist on knowledge being reduced to universals, but we should be wary of its use degenerating into becoming a form of "bullet-proofing" 62 against rival perspectives.

My main proposal in all this is not to insist therefore that we must just understand more about the disposal of the world - its arrangements and orderings as effected by the interplay of systems, culture, self and language. It is rather that we may understand disposal better alongside entertaining arguments about how systems, cultures, self and language help to produce and consume each other in the vexatious business of our exchanging attachments and establishing relations. Getting a handle on the disposal of the world - its ordering and arrangements - is no easy matter and especially so when many arrangements that facilitate extension live in the shadows and much ordering of selves is of a recessive nature. As I hope to have shown in illustrating my work of double-crossing, unearthing elisions, obviations and exclusions involves a close engagement both with theories of how we produce and reproduce the "things" of the world as well as with studies of how we set about consuming events. In this way we neither lose track of how much our own performances can matter, nor seek to jump over our shadows in the form of "scientific revolutions".

In exploring the manifold connections and links between culture, language, system and self, I have sought to clarify why we ought to avoid either accepting the conventional wisdom each of these carry, or hastily reject their ready-made ideas about arrangement and order. If we can agree for instance that language takes on aspects of system as well as culture, ${ }^{63}$ some comment might be made here on the ever-growing dependence in modernity on quantification. Specifically, it seems hard to refuse claims for matters like 
money and double entry to be also included as "languages". To the extent that either number or narrative can accomplish aspects of ostension, it should be noted that where numerical systems differ from alphabetic systems is over the need to keep and store. For example, in a clear example of the double nature of disposal, numbers not only bring into play their own forms of ordering and arrangement, they enable particular ways of forgetting. When we count up to ten apples, we happily efface oddities in shape, colour and taste. I hinted at this earlier with respect to how double entry formed itself into a system; that its gift (and its poison) lies in how its proclivity for monetary forms of transaction jettisoned the nature and content of other forms of information we might record. More than this, while some people might have to keep a few numbers in mind, in the form of budgets or cash in the bank, the wonderful thing about using numbers for our "outlook" is the way they numb us to the content they have excluded. In line with the streamlining nature of modernity, we continually find ourselves beset with new numbers; so much so that their proliferation engenders in us an intense need to erase older numbers from memory. Unlike words, which are attached (in both senses of the word), to forms of arrangement and ordering, numbers only indirectly inscribe our experiences with the world. Hence the common assumption that they are neutral, whereas in fact their ability to alert us instantly to the matter at hand is bought at the overall cost of numbing us to what is actually taking place.

More generally, what can be drawn out from these crossings and double-crossings? First I might emphasise I have said too little about other key ideas, particularly about notions of formal institutions, which has not only been a mainstay of sociology but is a key site for my own fieldwork. For instance, my research on corporations indicates how ethos, in its proper sense of the "bringing up" of members in terms of conduct, is undermined in the production of "ethical selves" 64 whenever discretion and trust is removed from staff by a growing reliance on bureaucratic procedures to provide transparency and accountability. So too, I have said little about markets - although my work on budgets in the past has clarified how these end up being used as an interface that severs profit goals from the narration of realities, ${ }^{65}$ creates different "worlds" for employers from that of staff, and seals off strategy from learning from those on the front line. ${ }^{66}$ Most wilfully, I have failed to offer a sociological analysis of management 67 - even though I have traced elsewhere the efficacy of disorganisation and unmanaging, ${ }^{68}$ critiqued the separation of policy from operations ${ }^{69}$, explained how discretion is centred in order to underpin authority, ${ }^{70}$ and shown how rhetoric about markets is used to disassociate line management from its oversight in one moment and then re-instated the next. ${ }^{71}$

What I can say to sum up, is that my key argument that self is always in extension goes beyond simply repeating how open we are to techniques or technologies. Rather it emphasises, instead, how unsighted each of us is to the effects of their incorporation as "attachments". ${ }^{72}$ As Marilyn Strathern has framed the issue, technologies work us as much as we work them. The most obvious correction that follows from this is to go on to admit the many ways in which culture and language intermingle; as much as we think of the former as "ours" and the latter as "mine", these are busy ordering and arranging behind our backs. For instance, while Derrida has pointed to a "violent hierarchy" in language in which one of two terms in an opposition "governs the other" or "has the upper hand", 73 such as white and black, or good and evil, Strathern has drawn attention to the dominant relations of ordering that arise from Euro-Americans invariably finding themselves in the mode of comparison. ${ }^{74}$ These matters certainly help to point to the 
more recessive ways domination works today; but, in raising the notion of language as landscape, a landscape which we look out from, I am suggesting they may yet be only threads leading back into the labyrinth.

In turning from self back to systems, the most glaring example of how language and culture are interwoven remains, even today, the long-held Western tying of reason to the deductive powers of formal logic; this fixation on validity not only denies intuition but, more surprisingly, excludes matters of truth. Equally glaring is the well known way "law", in its fetish for precedent, appears to drive out justice. However, what I have been pointing to is not so much a putative autopoiesis that could justify reification, but rather how systems like money and double entry (and hence profit budgets as well) "engross" themselves through the very processes and networks that enrol us. ${ }^{75}$ Only with the help of double entry, for instance, could capitalism become global and pull off the cultural feat of turning our debts into credits, ${ }^{76}$ rewarding those who forestall repayment with more credit and deem those who never borrow as uncreditworthy.

While my arguments over extension imply the importance of not falling into the trap of thinking of individuals as having agency without structure and its artefacts (including accounts in the form of proposals by the self to the self, for the self), it also seems imperative for sociology to avoid treating distributed systems as wholes, reifying say hybrids as new forms of life. What look to be key instead is to recognise how these offshoots of modernity install themselves as languages as at the same time they perform as cultures - albeit of an alien, inhuman kind - parasitically living off our complicity with a "violent hierarchy", or on our ability to incite each other into a "mode of comparison". At a minimum, closer attention should be given to how attachment to hybrid forms of artefacts intermingles with the cornucopia of relations upon which self-making draws. Going down this direction may also help unpick the chiaroscuro of modernity, illuminating how, and when, one picture of world gets "disposed" into another and how one self is figured in one moment and discarded for another view of self the next?

\section{Notes}

${ }^{1}$ Although the work of Georg Simmel anticipates much of this turn, the bestknown version of social construction is Peter Berger and Thomas Luckmann's The Social Construction of Reality: a Treatise in the Sociology of Knowledge (London: Allen Lane, 1966).

${ }^{2}$ Anthony Giddens uses "strategic conduct" in The Constitution of Society (Cambridge: Polity Press, 1984), pp. 288-293; 298, to discuss Paul Willis's study Learning to Labour (Farnborough: Saxon House, 1977) as emblematic how to concentrate analysis upon the "contextually situated activities of definite groups of actors". The existence of such definite groups has, however, come more and more into question, thus making performances that selectively deploy everyday institutions more critical. See Erving Goffman's The Presentation of Self in Everyday Life (New York, Doubleday, 1959). 
${ }^{3}$ As someone committed to the idea of persons as existing in extension (rather than seeing self as a self-contained being) "world" is a key term. In picking up for instance on Thomas Kuhn's error in understanding Ludwik Fleck's "thought collective" as evinced in the "thought styles" of an individual mind, Mary Douglas in How Institutions Think (London: Routledge, Kegan Paul, 1981), p.16, goes on to suggest, in line with Nelson Goodman and Howard Becker (and against other alternative terms such as "school of thought" or "thought collective"), that "the term 'world' has acquired the right sense". While Douglas expands this into art worlds, science worlds, music worlds and thought worlds, what I wish to do with the notion of extension is to find a way to theorise "world" in ways that avoid oscillating between notions of groupthink and the figure of the individual mind. 4 Seeking to abandon one truth regime may be possible only by shifting to another truth regime. As Derrida points out in Margins of Philosophy, trans. Alan Bass (Hemel Hempstead: Harvester Wheatsheaf, 1981), p. 135, “. . the simple practice of language ceaselessly reinstates the new terrain on older ground". ${ }^{5}$ Elsewhere I have argued that Heidegger's way of questioning ends up, in practice, as a form of double-crossing. See Rolland Munro, "The Remains of the Say: Zero, double-crossing and the landscaping of language', Lournal for Cultural Research, 8(2), 2004, pp. 183-200.

${ }^{6}$ Anthony Giddens is just one example of this trend, see Modernity and SelfIdentity: Self and Society in the Late Modern Age (Cambridge: Polity Press, 1991). Some of those following Michel Foucault's idea of governmentality would also seem to make the mistake of thinking of people have now actually been made into individuals, see for instance Nikolas Rose Governing the Soul: the shaping of the private self (London: Routledge, 1990).

${ }^{7}$ John Law's After Method: Mess in Social Science Research (London: Routledge, 2004) addresses complexities in research, but what I have to say is more in line with Marilyn Strathern's felicitous phrase "indirection", which implies an "openness" of engagement to contingencies in the field.

8 Talcott Parsons, "The Present Status of "Structural-Functional" Theory in Sociology." In Talcott Parsons, Social Systems and the Evolution of Action Theory. New York: The Free Press, 1977, p. 101. See also Talcott Parsons, The Social System. New York: The Free Press, 1951.

${ }^{9}$ At the time of writing the Daily Mail is charging Ralph Milliband, the sociologist father of the UK Leader of the Opposition, with treason on the grounds he wanted to do away with the establishment. As I remember, it wasn't only Marxists who wanted this. Inasmuch as "the establishment" was seen as a key part of the problem, almost everyone wanted what they called "the system" to be changed!

${ }^{10}$ Consider the following syllogism. All swans are white; Leda is a swan: therefore Leda is white. The conclusion is incontrovertible provided the first two assumptions are true. This is what is meant by truth preserving. However, if you know your Greek mythology, the idea that Leda is a swan is not only false, it is the god Zeus who takes on the form of the swan.

11 David Harvey, A Companion to Marx's Capital (London: Verso, 2010).

12 Rolland Munro, "Knowledge systems", PhD thesis, University of Edinburgh, 1986. David Graeber's Debt: The First 5,000 years (Melville House, 2011) has contested the idea that barter came before money, but there are two caveats that 
should be added to this claim. First historical research links the origins of money in Babylonian times to the invention of writing; hence records for barter prior to this time would be unlikely to exist; see Mahmoud Ezzamel and Keith Hoskin 'Retheorizing accounting, writing and money with evidence from Mesopotamia and ancient Egypt.' Critical Perspectives on Accounting, 13(3), 2002, pp. 333-367. Second, we should not expect to find systems of barter, since my claim amounts to saying money is most likely the first system (preceding even the technology of writing). However, this said, my main argument is that money as a system awaits the appearance of double entry as a system before it can really take off and justify claims for its having autopoeisis within global capitalism.

13 Rolland Munro, ibid.

14 Rolland Munro, ibid.

15 John Urry, 'Inhabiting the Car', The Sociological Review, 54: s1, 2006, pp. 17-31. ${ }^{16}$ Sociology's interest in the local was not new, going back to the work of the Chicago school on urban areas in the 1930s. Particularly influential on ethnographers was W. Foot Whyte's Street Corner Society, (Chicago: University of Chicago Press, 1949).

17 Edgar Schein's Organizational Culture and Leadership: A Dynamic View (San Francisco, CA: Jossey-Bass, 1992). exemplified the former and Van Mannan's Tales of the Field: On Writing Ethnography (Chicago: University of Chicago, 1988) was particularly in vogue for the latter. The better work in the genre includes Kundra's Engineering Culture, Control and Commitment in a Hi-Tech Corporation (Philadelphia, PA: Temple University Press, 2006), while Peter Frost et al's Organisational Culture (Beverley Hills: Sage, 1985) is a useful collection. 18 Bourdieu draws on the notion of habitus to reconcile what he takes to be "objective" aspects of structuralism with "subjective" aspects of individualism and argues that this ".. means that our object becomes the production of the habitus, that system of dispositions which acts as mediation between structures and practice; more specifically, it becomes necessary to study the laws that determine the tendency of structures to reproduce themselves by producing agents endowed with the system of predispositions which is capable of engendering practices adapted to the structures and thereby contributing to the reproduction of the structures." Pierre Bourdieu, 'Cultural Reproduction and Social Reproduction'. In J. Karabel and A. H. Halsey (eds) Power and Ideology in Education (Oxford: OUP, 1977), p. 487, emphasis added. See also Pierre Bourdieu, Outline of a Theory of Practice (Cambridge: CUP, 1977). While his use of the term does vary, the original meaning comes from Marcel Mauss, the nephew and protégé of Durkheim.

19 Reflecting an earlier period of immersion in an institution prior to studying for my doctorate, Tony Cohen advised me that what I was after was better notated by the notion of ethos. I still think ethos is a useful term to denote the kind of "upbringing" one can experience in an institution, a kind of second skin to habitus, but I also have noted elsewhere how many studies of the social get short-circuited to conversation between persons and elide the circulation and exchange of materials, see Rolland Munro, 'Calling for Accounts: Numbers, monsters and membership', The Sociological Review. 49(4), 2001, pp. 473-493. ${ }^{20}$ Rolland Munro, 'Managing By Ambiguity: An archaeology of the social in the absence of management accounting', Critical Perspectives on Accounting, 6, 4, 
1995, pp. 433-482.

21 The idea of matter being "out of place" is attributed to William James and is discussed at length in Mary Douglas, Purity and Danger: an analysis of taboo (London: Routledge, Kegan Paul, 1966).

22 Mary Douglas and Baron Isherwood, The World of Goods: Towards an Anthropology of Consumption (London: Routledge, 1979).

${ }^{23}$ Mary Douglas's approach to culture (as well as group) is suggestive as to how people advertise to others aspects of belonging, but her emphasis on goods acting as symbols imports a reliance on systems of signs being well understood. I thought this smuggled back in the questionable notion of shared values and hence undermined the novelty of her emphasis on display. The idea that people were bonded through a common knowledge of symbols not only re-iterates older ideas of commonality from learning a language, it obscured the opportunity for ethnographers to pick up on observable and checkable shifts in the ordering of material arrangements. More critically, in her tendency to overlook the disposal of power in all its distribution and its interdependencies, Douglas infers too readily that commonalities in display reveals identity. ${ }^{24}$ Harold Garfinkel, Ethnomethodology (Engelwood Cliffs, NJ: Prentice-Hall, 1967), p. 35. The phrase is used by Garfinkel in direct opposition to Kant's emphasis on "the universe within". The distinction goes to the heart of the difference between ethics and ethos, the former being usually taken to be codification of morals "inside" persons and the latter belonging to the moral world "outside".

${ }^{25}$ Rolland Munro, 'Calling for Accounts: Numbers, monsters and membership', The Sociological Review, 49, 4, 2001, pp. 473-493.

${ }^{26}$ Marilyn Strathern, Partial Connections (Savage, Maryland: Rowman and Littlefield, 1991).

27 Rolland Munro, 'The Cultural Performance of Control', Organization Studies, 20, 4, 1999, pp. 619-639.

${ }^{28}$ Rolland Munro (2004) 'Punctualising Identity: Time and the demanding relation', Sociology, 38, 2, 2004, pp. 293-311. In distinction to Garfinkel's, op cit, emphasis on members being "visible and accountable", I use "visible and available" to develop the notion of technology having made us a "standing reserve". See Martin Heidegger, 'The Question Concerning Technology', in David Krell (ed.) Basic Writings: Martin Heidegger, pp. 311-341 (London: Routledge, 1993).

${ }^{29}$ Donna Haraway, 'A manifesto for Cyborgs: Science, Technology and Socialist Feminism in the 1980s', Socialist Review 80, 1985, pp. 65-107.

30 Here I looked at pre-enlightenment forms of melancholy, tracing its artefacts such as the stump of tree and the "stewpond", positioned well away from the house with all its attendant demands. Rolland Munro, 'Outside Paradise:

Melancholy and the Follies of Modernisation', Culture and Organisation, 11, 4, 2005: 275-289.

${ }^{31}$ Rolland Munro, 'The Consumption View of Self: extension, exchange and identity'. In S. Edgell, K. Hetherington and A. Warde (eds) Consumption Matters: the production and experience of consumption (Sociological Review Monograph, pp. 248-273. Oxford: Blackwell, 1996).

32 Rolland Munro, 'Organisation, Listening and the Aesthetics of Disposal', Tamara: Journal of Critical Organization Science, 6: 2, 2007. 
33 Multiple selves will not do. We would need too many of them! We move not simply from Schutz's ruthless self by day; we are travelling incessantly, back and forth, from one involuted space to another, one moment calculating a percentage, the next extolling a colleague to collaborate.

${ }^{34}$ As Louis Wacquant notes in 'Following Pierre Bourdieu into the Field', Ethnography, 5(4), 2004, Bourdieu's elaboration of habitus looks back to a rural peasantry who were working the land in Bearn in France and were, according to his reports, too stuck in their ways to be marriageable to the women of the region - many of whom had moved on by taking up work in the nearby towns. 35 Martin Heidegger, Being and Time, trans. John Macquarrie and Edward Robinson (Oxford: Basil Blackwell, 1962).

${ }^{36}$ Even given these concessions, there are difficulties for transcending our upbringing. For instance, whereas Heidegger, ibid, hung onto the idea that we could - if with difficulty - move away from our thrownness towards a kind of enlightenment, Foucault saw thought as locked into "truth regimes". On my analysis of extension, this last point suggests that self - whatever that is - cannot step in and out of a truth regime at will. To the contrary, at best all that might be accomplished is shifting from one truth regime to another. This is on the face of it an impasse. Yet would there not be slippage in the passage from t'other? And would this slippage not prove enough? As with the rabbit and the duck in Gestalt experiments, would not the experience of the one question the other, even if only fractionally?

${ }^{37}$ Martin Heidegger, 'The Question Concerning Technology', op cit.

38 Rolland Munro, Punctualising Identity, op cit.

39 Joanna Latimer and Rolland Munro, 'Driving the Social'. The Sociological Review, 54: s1, 2006, pp. 32-53.

40 Motility should not be confused with fluidity. While it is possible this seamless shifting of worlds may stabilise our individuated sense of "sovereignty", Joanna Latimer and I have also speculated how motility may augment stabilities in power. 'Keeping \& Dwelling: relational extension, the idea of home, and Otherness', Space \& Culture, 12, pp. 317-331. Against the world becoming "liquid", as Zygmunt Bauman has pressed in Liquid Modernity (Cambridge: Polity Press, 2000), we suggest how world shifting can act as a form of defence. By means of the common, and more shameless, form of double-crossing, those in authority positions can be seen to undercut critical attack by shifting the ground they represent. Accused of being up to something, they shift their attachments and make themselves out to be doing something quite other; thus discrediting the attack as misinformed or misconceived.

41 Martin Heidegger, 'The Question of Technology', op cit.

42 Although language is never private, Derrida's discussion of the ear in 'Tympan', Margins of Philosophy, op cit, offers insight into how some of the iterations of others become modulated and, eventually, come to be heard in our own voice.

43 This nexus suggest the impossibility of our stepping freely out of any particular cultural set of orderings and arrangements, since these are already bequeathed in the ways we look at things. As I hinted before, in discussing self, the problem we have is that of getting stuck in one mode of being or being too fixed in our outlook. Foucault may be right in insisting that all we can do is to step from one truth regime to another and, to be sure, in respect of the fashion for talking about shifting perspectives, it 
seems all too easy simply to become prey to other ideologies, or as noted earlier, fall back as Derrida has pointed out onto older ground?

${ }^{44}$ Some overlap between European movements and American Pragmatism have been noted variously in recent years. For instance, Ian Hacking in Scientific Revolutions (Oxford: OUP, 1981), p. 131, points out that one of the "greatest novelties" of the work of C. S Peirce is the idea that "man is language".

45 The operation to give someone a pig's heart certainly is inserted inside the body, but reassurances are usually given that this will not alter their personhood. 46 Jerome Bruner, Actual Minds, Possible Worlds (Boston: Harvard University Press, 1985).

47 Rolland Munro and Olga Belova, "The Body in Time: Affect and the 'interruption' of narrative', The Sociological Review, 55 (s2), 2008, pp. 87-99. 48 Rolland Munro, 'Just When You Thought It Safe To Enter the Water: Accountability, language games and multiple control technologies', Accounting, Management and Information Technologies, 3 (4), 1993, pp. 249-271.

${ }^{49}$ Heidegger's discussion of the bridge is germane in 'Building, Dwelling, thinking', Basic Writings: Martin Heidegger, op cit. Before the bridge is built, we see a stream flowing in one direction. After it is installed, however, we see the banks standing in opposition to each other. The bridge connects the banks in one way, but to do so it also separates them in another. Metaphorically, what language can do is remember such nuances of form without us seeming to need to do so. A good example is the way grammar turns me into the subject "I" and what I am holding or using into an object "it", giving me sentience and denying any agency to what is in the hand.

50 Rolland Munro, 'The Consumption of Time and Space: Utopias and the English romantic garden' in M. Parker (ed.) Utopia and Organization, pp. 128-154, (Sociological Review Monograph, Oxford: Blackwell, 2002).

51 Martin Heidegger, The Age of the World Picture' in The Question Concerning Technology and other Essays, trans. William Lovitt (New York: Harper \& Row, 1977). It should be clear - insofar as this landscaping of affect does in practice create a voice that makes language uniquely mine - that we are talking about something very different in kind from the conceptual cartography undertaken by ordinary language philosophers. Important as it is on occasion to "systematize" language, their distinctions tend to abstract understandings of language away from how it works on the "ground" - Heidegger's key term.

52 Some greater depth can be given to Saussure's oppositions through the recognition of combinations of terms, see Pieter Fourie (2001). Media Studies Volume 2: Content, Audiences and Production. Lansdowne: Juta Education. However, even combinations of binaries do not go far enough to capture the underlying forms from which we look out, or help us unpick the ways language moves us about in our efforts to grasp what is happening in the world.

${ }^{53}$ Rolland Munro, 'Double-crossing the Landscapes of Philosophy: Conjoining the transparency of 'things' with the veil of language'. In C. Jones \& R. ten Bos, Philosophy and Organisation, pp. 184-200 (London: Routledge, 2006).

54 David Appelbaum, The Stop, State University of New York, 1995.

55 Mary Douglas, Implicit Meanings: Essays in Anthropology (London: Routledge, Kegan Paul, 1975). 
${ }^{56}$ Larry Lauden, 'A Problem Solving Approach to Scientific Progress' in Hacking, op cit, p. 151.

${ }^{57}$ Hacking, op cit, discusses Imre Lakatos' concept of competing research programmes as a way of refining Thomas Kuhn's notion of "revolution" in scientific communities in The Structure of Scientific Revolutions (Chicago: Chicago University Press, 1970). Instead of theories going straight to the "dustbin" of history, he suggests how scientists gradually desert a research programme when too many anomalies become evident.

58 Talcott Parsons, op cit.

59 Roger Jeffery, 'Normal Rubbish: Deviant patients in casualty departments', Sociology of Health and Illness, 1(1), pp. 90-107, 1979.

60 Randall Collins, Four Sociological Traditions (Oxford: OUP, 1985).

61 Joanna Latimer and Beverley Skeggs (2011) The Politics of Imagination: keeping open and critical. The Sociological Review 59(3) pp. 393-41.

62 Marilyn Strathern, "Bullet-proofing: A tale from the United Kingdom", in A. Riles (ed.), Documents. Artifacts of modern knowledge (Ann Arbor: The University of Michigan Press, 2006) pp. 181-205.

63 The model of "bootstrapping" that may be exemplary here is Barry Barnes 'Social Life as Bootstrapped Induction', Sociology, 17(4). In bringing his arguments back to Mary Douglas's observations about culture, noted earlier, some qualification is necessary; for example it is hard to be sure whether some words are never spoken because they are too sacred or too profane.

64 Joanna Latimer, The Conduct of Care (Oxford: Blackwell, 2000). Latimer explains how today's ethos in the NHS has been turned towards the production of "ethical selves". The importance of her finding is that she shows how this kind of ethos gets rid of a sense of responsibility for the care of others.

65 Rolland Munro, 'After Reality: rubbing the talk up against the numbers'. In H.K. Rasmussen (ed.) AOS Conference on Accounting, Time and Space, pp. 509-538, (Copenhagen: Copenhagen Business School, 1997).

66 Rolland Munro, Enabling Participative Change: The impact of a strategic value', International Studies in Management and Organization, 21(4), 1992, pp. 52-65.

67 The tropes of production and consumption suggest "a world at our disposal"; the former as one to appropriate and exploit, and the latter as one to celebrate and enjoy. Yet since markets fail, and since planning is subject to the law of unintended consequences, there is an all-important proviso. This is the current argument that everything carries "risk", from global disasters to employing people, and need to be "managed". Hence the rise and rise and rise of managers over the last century. Regrettably, this loop of entrusting the "arranging" of procedures or the "ordering" of products to managers ends up with management presenting itself as the only solution to problems managers themselves create. 68 Rolland Munro, 'Unmanaging/Disorganization', ephemera: critical dialogues on organization, 1(4), 2001, pp. 395-403.

${ }^{69}$ Rolland Munro, 'Connection/ Disconnection: Theory and practice in organization control', British Journal of Management, 8 (Special Issue), 1997, pp. $43-63$.

70 Rolland Munro, 'Power and Discretion: Membership work in the time of technology', Organization, 6(3), 1999, pp. 429-450.

${ }^{71}$ Rolland Munro, 'Belonging on the Move: Market rhetoric and the future as 
obligatory passage', The Sociological Review, 46(2), 1998, pp. 208-243.

72 I have not brought back into this paper how recent systems thinking might overlap with my own analysis. In this respect one of the most exciting and incisive pieces of writing is Nigel Thrift's 'The insubstantial pageant: producing an untoward land' (Cultural Geographies 19,2: p.144) where he focuses on "the formation of a long-term infrastructural project" which has required the "construction of what we might term an expressive infrastructure in that it is meant to act as a pipeline for affect and imagination". As different perspectives coming from opposite angles, it would be good to see how his notion of a new kind of "land" and my ideas on "landscape" could work together?

73 Jacques Derrida, Positions, trans. Allan Bass (Chicago: Chicago University Press, 1972), p. 41. As Derrida goes on to remark, "overturning" a classical opposition of terms has to be more than a phase since "the hierarchy of oppositions always reasserts itself", p. 42.

74 Marilyn Strathern, 'Gender: division or comparison?', in Kevin Hetherington and Rolland Munro (eds) Ideas of Difference (Sociological Review Monograph, Oxford: Blackwell, 1997).

75 Michel Callon, 'Some Elements of a Sociology of Translation: Domestication of the Scallops and the Fishermen of St Brieuc Bay', in John Law (ed.) Power, Action and Belief: A New Sociology of Knowledge, pp. 196-233, (London: Routledge \& Kegan Paul 1986).

${ }^{76}$ I am indebted to David Mitchell's The Thousand Autumns of Jan de Cleef for this insight. While he does not mention double-entry, his hero is a Dutch bookkeeper. 